\title{
Age- and Gender-dependent Differences of Asylum Seekers' Information Behavior and Online Media Usage
}

\author{
Franziska Zimmer \\ Heinrich Heine University \\ Düsseldorf, Germany \\ franziska.zimmer@hhu.de
}

\author{
Katrin Scheibe \\ Heinrich Heine University \\ Düsseldorf, Germany \\ katrin.scheibe@hhu.de
}

\begin{abstract}
This investigation is about asylum seekers' information and communications technologies (ICT) as well as online media usage and their motivation to apply a system after arriving in their destination country. As the asylum seekers left their homeland and need to rebuild their life in a different country with a new culture and a foreign language, their (information) behavior might have adapted to the given circumstances. What online systems and social media do asylum seekers apply to satisfy their need for information, entertainment, social interaction, and self-presentation? How do different age groups behave? Are there gender-dependent differences?

A mixed method approach with semi-structured interviews while filling in a questionnaire was applied. In total, 45 asylum seekers from the Middle East were interviewed in Germany. The smartphone is an essential media for communication and integration for the asylum seekers. Adults mainly use social media for information whereas children use social media for entertainment purposes, as many adults do not find time for it; and, both groups for social interaction.
\end{abstract}

\section{Introduction}

In 2015 a rising number of people fleeing their home country arriving in the European Union (EU) led to the European migrant crisis, or refugee crisis. 1.2 million first-time asylum applications were made in 2015 in the EU, which is more than double the amount of 2014. Germany, Hungary, Sweden, and Austria received two-thirds of all applications in 2015. In 2018, there were still about 600,000 first time applications [11]. The immigrants that arrive in Europe include asylum seekers and economic migrants. The term "economic migrant" describes a person who leaves their home country because of economic reasons, for example to flee from poverty or to find better job opportunities. Asylum seekers are individuals seeking international protection; a refugee is someone who fled their home country and cannot return, fearing persecution because of race, religion, or nationality. Therefore, every refugee is an asylum seeker but not every asylum seeker will be recognized as a refugee [4].

Statistically, most of the migrants came from regions south and east of Europe, additionally Africa and the Greater Middle East [27]. The Middle East is constituted of several countries centered in West Asia, and includes Turkey and Egypt, with some definitions including the South Caucasus. The largest ethnic groups are Arabs, Turks, Persians, Kurds, and Azeris. Since 2013, the highest number of all refugees fleeing to the EU originates from Syria (29\% in 2015; $13.9 \%$ in 2018). In 2018, the second largest group were Afghan refugees (7.1\%); Iraqis (6.8\%), Pakistanis and Iranians (4.3\% and $4.0 \%$ respectively) make up the next largest groups [16].

The asylum seekers fled from their homeland, arriving in a new country, where they develop their own information horizon and social environment. Their situation, living conditions, and circumstances changed. Some are separated from their family members, have to establish new social contacts and try to stay in touch with their acquaintances and relatives. They have to learn a new language for job opportunities. Since the asylum seekers need to build their new life, they have to adapt to new situations: What needs do they have [37]? What is their information behavior? Are they included in the new culture of the European host countries?

\subsection{Asylum seekers, ICT, and (social) media}

A conjoint experiment in 15 European countries asked 18,000 voters what types of asylum seekers they are willing to accept, with the results indicating that asylum seekers with a higher employability, therefore judging them by their possible economic contributions, receive more support from the population [6]. A study 
[34] assessed the digital skills of refugees during job orientation in Germany. The authors concluded that targeted courses for those skills will be beneficial for refugees to make labor market integration easier. Information and communications technologies (ICT) play an important role in this, as those products and services (e.g. personal computers, smartphones, search engines, social media, messaging services) enable their users to search for, find, understand, and apply information. ICT skills to use digital technologies efficiently are a growing requirement for various occupations in the majority of countries [30]. Furthermore, refugees "use their mobile phones for interactions regarding social and financial issues; for business or work purposes; for education, divertissement, church, safety and advocacy purposes" [9:2166], as a study about urban refugees in South Africa highlights. Personal needs of the refugees make it difficult to separate themselves from their smartphones. Especially young migrants use their smartphones as a medium to participate with other youths locally and globally and to have a sense of refuge [29].

Another study focused on information practices of refugees and communication strategies in the integration process, however not in relation to ICT [25]. It was found that asylum seekers do receive necessary task-related information when arriving in a new country, in this case Sweden. Certainly, those asylum seekers in Sweden, are later left alone, since officers in the state agencies cannot provide personal guidance because of strict rules, impeding the acquisition of general orienting information and guidance. Different approaches are taken to help asylum seekers settle in their new countries with the use of technology $[5,7,39]$ and applying HCI research in line with workshops to help researchers learn how to interact with asylum seekers [1]. Other research focused on an approach to use computer clubs in a Palestinian refugee camp to foster learning, social networks, and integration [2].

Research conducted on the integration of refugees in the Netherlands with the use of social media stresses the relevance for the acquisition of language and cultural competences. The refugees were able to build bonding and bridging social capital [3]. An additional investigation focused on the role of social media in the migration decision of refugees, meaning the information they gathered before and during migration to decide where they want to settle. Information that comes from existing social ties and is based on personal experience is considered to be most trustworthy [15].

\subsection{Research framework}

This is the gap our study fills. The presented investigation is about what information and communications technology (ICT) asylum seekers utilize, and what kind of social media and other online media they use when settling in a new country, in this case Germany.

Case and Given [12:48] state, "context and situation are important concepts for information behavior research.” In line with Pettigrew, Fidel, and Bruce [28:44] we define "information behavior" as "how people need, seek, give, and use information in different contexts, including the workplace and everyday living." Thus, our approach does not only consider information seeking and consumption behavior (as often found in information science), e.g., $[13,21])$ but information production and dissemination behavior as well. Wilson [38:49] also defines "information behavior" in a rather broad way: "Information Behavior is the totality of human behavior in relation to sources and channels of information, including both active and passive information seeking, and information use." Human information behavior is embedded in the users' "information horizons" [33] including the users' social contacts and networks (their social capital) as well as their concrete contexts and situations. As on social media and messaging services both, information production as well as information seeking and reception behavior, is always given, only this broad definition of information behavior is sufficient for our research.

As media provide different kind of information, it also satisfies a variety of needs. The Uses and Gratifications Theory (U\&GT) defines four central motives for people to apply different kinds of mediain this case social media other online media, and messaging services: information, entertainment, social interaction, and self-presentation [24,10]. Information means the motive of giving or finding knowledge (including everyday information knowledge) [26]; personal identity is related to our motive to define our identity or to present ourselves (e.g., constructing an own Facebook page); entertainment comprises escaping from problems, relaxing, or filling time; social interaction is the motive to interact with other people and to maintain social capital. Users derive a sense of gratification when using the different forms of media, making this theory the basis for our research study: How do asylum seekers satisfy their needs for the different motivations? What kinds of online media, especially social media, do they apply? 
Since Germany received the largest number of asylum applications for all years, including 2018 with around 161,931 first time asylum applicants and North Rhine-Westphalia being the Federal state (Bundesland) with the highest number as well (39,579; 24.4\%), the research was conducted in this area. Most of the asylum seekers arriving in Germany 2018 originate from Syria (27.3\%), Iraq (10.1\%), Iran (6.7\%), Nigeria (6.3\%), Turkey (6.3\%), and Afghanistan (6.1\%) [17].

As soon as migrants arrive in Germany, they have to report on seeking asylum in the country [18]. Then, the asylum seekers receive a proof of arrival (Ankunftsnachweis) which grants them access to state benefits. The Federal Office decides, based on the German Asylum Act (Asylgesetz) between four forms of protection: entitlement to asylum (Art. 16a of The Basic Law (Grundgesetz)), refugee protection ( $§ 3$ of the Asylum Act), subsidiary protection ( $\S 4$ of the Asylum Act), or a ban on deportation ( $\S 60 \mathrm{~V}+\mathrm{VII}$ of the Residence Act). In our study, all interviewees received the "entitled to asylum" status.

Research about digital skills and information behavior as well as the social media usage of refugees and asylum seekers is still in its beginnings, especially in Germany [31], making this research necessary to understand asylum seekers application of ICT, their perceived skills, as well as their motivations to use (online) media. Studies suggest that the genders as well as generations behave on and use social media differently [8,19,23]. According to Joiner et al. [22] women use the internet and social media to get connected with other people and to communicate with them, whereas men use it for entertainment purpose respectively gaming. Looking at the user-generated content by gender, men are more likely to discuss public events (e.g. sports and politics) whereas women tend to share personal matters (e.g. family related) [36]. The United Nations High Commissioner for Refugees [35:16] reports about challenges of connecting refugee women and the elderly as they "are less likely to have access to mobile phones and the internet." Different generations were confronted with the internet and ICT in distinct stages of life and therefore had more or less the opportunity to adopt it to their everyday life [20].

This study analyzes the differences of ICT and social media usage of refugees among the age and gender groups accordingly. All in all, we arrive at the following research questions:

RQ1: Can gender- and age-dependent differences in the application of ICT be observed?

RQ2: How do asylum seekers perceive their skills to accurately use ICT?
RQ3: What social media and other web services do asylum seekers apply to satisfy their needs for information, entertainment, social interaction, and selfpresentation? Are there gender- and age-dependent differences?

\section{Methods}

As the analysis of asylum seekers' information behavior is a very current and highly topical research area, there is no established theory to illustrate the interrelationships between asylum seekers (including the aspects of gender and generation), their information behavior, and their ICT as well as media usage. Beside the data collection and data analysis, researchers are permanently required to conduct coding, due to the steady arrival of new data. Indeed, as there were new and unexpected data in the first interview round (in Dorsten), we added new aspects to our research questions and subsequently into the interview guide of the next interviews (in Düsseldorf, Moers, and Wesel).

To gather the necessary data and information, a mixed-method approach [14] was applied. For qualitative data, semi-structured face-to-face interviews were performed and quantitative data were collected with a questionnaire. First, different associations, institutions, and organizations as well as city governments in North-Rhine Westphalia were contacted as early contact points. It was recommended to interview asylum seekers from German language classes in order to properly communicate with them. We were able to interview a number of 25 adults in Dorsten and Düsseldorf aged between 21 and 55 years in November and December 2018 as well as in February 2019. All interview partners were attendees in German language courses of different levels (A1 (beginner) to C1 (proficiency)), who voluntary took part in our interviews. For asylum seekers who were not fluent enough in German yet, an Arabic native speaker was present. The interviews took around 15 to 30 minutes each. During the interviews, parents often mentioned their children using a specific service they were not using. Therefore, after a first analysis of the collected data, a second round of semi-structured interviews and filling in questionnaires was performed with 21 children and adolescents aged between 8 and 18 years. The procedure took place in April 2019 during a holiday care program for children of asylum seekers in Wesel and Moers. All children took part voluntarily in the interviews. If someone was not able to understand the interview-questions the children helped each other with the translation or there was the opportunity to speak English. In total, 45 people from Syria $(\mathrm{N}=23)$, Afghanistan $(\mathrm{N}=8)$, Turkey $(\mathrm{N}=5)$, Iraq 
$(\mathrm{N}=4)$, Iran $(\mathrm{N}=2)$, Azerbaijan $(\mathrm{N}=2)$, and Lebanon $(\mathrm{N}=1)$, were interviewed. The questionnaire as well as the interview guides focused on the asylum seekers ICT and (social) media service usage in relation to the U\&GT [10] and the summarized four central motives to use media by [24], which are information, entertainment, social interaction, and self-actualization. Self-actualization was transformed to self-presentation for producing content [32].

First, the interviewees were asked for demographics, their country of origin, age, gender, and educational level. They should also state what ICTs (smartphone, Internet, TV, laptop, tablet, PC) they are using and how they rate their skills to use ICT (especially their smartphone) and (online) media on a 5-point Likert-scale. Afterwards, a question asked what social media and messaging services (e.g. WhatsApp, Facebook, YouTube, Instagram, Twitter, Reddit, Live Streaming, TikTok) as well as further online media (news websites, online encyclopedias like Wikipedia) or ICT devices they are using to get information (knowledge). For the entertainment dimension, the interviewees were asked about which kind of social media (see above) and online media (e.g. Apps, streaming services like Netflix) they like to use for fun and relaxation. Social interaction means all kinds of contact with relatives, friends or even strangers on the Internet. Therefore, the participants were asked which social media or messaging services (see above) they use to get in contact with other people to satisfy their need for social connection. For the self-presentation aspect, the asylum seekers were asked on which social media and messaging systems they share pictures, videos, or postings and about their motives to produce online content.

The interviews were transcribed by the two researchers. For this research article, the texts had to be translated from German to English, whereby most sentences are reproduced analogously to their meaning because of the language deficit of the interview partners.

\section{Results}

In our study, we interviewed 45 asylum seekers from the Middle East. First, some demographic data is presented, which is followed by the statistical analysis of the gender- and age-dependent differences regarding the applied ICT, as well as the perceived ability to handle those ICT. Furthermore, the gender- and agedependent differences regarding the motivations suggested by the Uses and Gratifications Theory were statistically analyzed applying SPSS.

As for the age distribution, two groups were formed: children and teens aged 19 and below (46.7\%) as well as adults aged 20 and older (53.3\%). This distribution matches the one of the first time asylum applicants in Germany, as around 44\% of all applicants are less than 18 years old [16]. 28 (62.2\%) of our participants were male and 17 (37.8\%) female. 70\% of all first time asylum applicants in Germany are male for the age group 14-34, and 59\% for the age group 3564 [4], matching our distribution. Most of our participants came from Syria (51.1\%), Afghanistan (17.8\%), and Turkey (11.1\%). As for the education of our participants, 17 (70.8\%) of the adults had a high school diploma or higher education. Nine (42.9\%) of the young participants are currently in primary school, eleven (47.6\%) are in middle or high school, and two $(9.5 \%)$ attend a vocational college.

\subsection{Applied ICT and media}

Overall, the most used ICT products are the smartphone (95.6\%) as well as the internet (95.6\%), followed by the TV (88.9\%). "I do not watch movies on television, most of the time I use my smartphone or laptop for it," explained one boy (IP26); "I prefer to use my smartphone instead of the computer, but I am not able to use all the functions on my smartphone that I want to use," claimed one girl (IP29). Another girl states (IP28) "what am I supposed to do on the notebook that I am not able to do on the smartphone?” highlighting the importance of smartphones for boys and girls, especially in contrast to other ICT like tablets, the TV, and PCs. Men and women seem to share this opinion: "Everything is on the smartphone; on YouTube, news, information, everything,” explains one man (IP1). Another man (IP4) proclaims "you can do everything on your smartphone, why use something else." Other adults had conflicting thoughts about smartphones and media in general: "I don't have any free time to use media, I need the time to care for my children as well as learning German," as one father states (IP7). "When the kids are sleeping I am able to use my smartphone and have a little bit of free time” confirms a mother (IP14). One man (IP25) even contrasts: "In Syria, I played a lot with my smartphone, now, in Germany, I am not interested anymore." Laptops (46.7\%) and the radio (42.2\%) are utilized as well, whereas not as much. Ranking last, we find tablets (31.1\%), landline telephones (24.4\%), and the PC (17.8\%). Here, one woman (IP10) states "I do have a tablet, but I do not use it.”

3.1.1. Gender-dependent differences. Genderdependent differences regarding the use of ICT can be obtained from Table 1 . More female (100\%) than male (92.5\%) participants apply smartphones and use the internet. PCs (male 21.4\%, female 11.8\%), laptops 
(male 57.1\%, female 29.4\%) as well as tablets (male $39.3 \%$, female $17.6 \%$ ) are chosen more often by male participants.

Table 1. ICT and media usage of the genders

\begin{tabular}{lcc}
\multicolumn{1}{c}{ ICT } & $\begin{array}{c}\text { Male } \\
\text { N=28 }\end{array}$ & $\begin{array}{c}\text { Female } \\
\text { N=17 }\end{array}$ \\
\hline Smartphone & $92.9 \%$ & $100 \%$ \\
\hline Internet & $92.9 \%$ & $100 \%$ \\
\hline TV & $85.7 \%$ & $94.1 \%$ \\
\hline Laptop & $57.1 \%$ & $29.4 \%$ \\
\hline Radio & $39.3 \%$ & $47.1 \%$ \\
\hline Tablet & $39.3 \%$ & $17.6 \%$ \\
\hline Landline & $21.4 \%$ & $29.4 \%$ \\
\hline PC & $21.4 \%$ & $11.8 \%$ \\
\hline
\end{tabular}

3.1.2. Age-dependent differences. Considering the age-dependent differences of the application of ICT and media, a few differences can be observed (Table 2). More adults (100\%) use smartphones than the younger ones $(90.5 \%)$. If tablets $(42.9 \%)$, PCs $(23.8 \%)$ and laptops (57.1\%) are concerned, they are preferred by the younger users in contrast to the older ones (tablet 20.8\%, PC 12.5\%, laptop 37.5\%), even though they are losing importance for the children as well.

Table 2. ICT and media usage of the age groups.

\begin{tabular}{lcc}
\multicolumn{1}{c}{ ICT } & $\begin{array}{c}\text { Children } \\
\mathrm{N}=21\end{array}$ & $\begin{array}{c}\text { Adults } \\
\mathrm{N}=24\end{array}$ \\
\hline Smartphone & $90.5 \%$ & $100 \%$ \\
\hline Internet & $95.2 \%$ & $95.8 \%$ \\
\hline TV & $90.5 \%$ & $87.5 \%$ \\
\hline Laptop & $57.1 \%$ & $37.5 \%$ \\
\hline Radio & $38.1 \%$ & $45.8 \%$ \\
\hline Tablet & $42.9 \%$ & $20.8 \%$ \\
\hline Landline & $23.8 \%$ & $25.0 \%$ \\
\hline PC & $23.8 \%$ & $12.5 \%$ \\
\hline
\end{tabular}

\subsection{Perceived ability to use ICT and media}

The participants were asked to rank their perceived ability to handle different ICT on a Likert-scale from 1 ("not able to") to 5 ("fully efficient"). The findings are displayed as Boxplots (Figure 1). It can be observed that boys and girls do not differ in their perception of their skills to use ICT (median of 4, IQR 2) with the lowest value being a 3 . However, adult men and women do differ quite a bit in this regard. Men overall display greater confidence in their ability (median 4, IQR 2) with the lowest value at 3, whereas women are not as positive (median 3, IQR 2) with the lowest value at 2 .

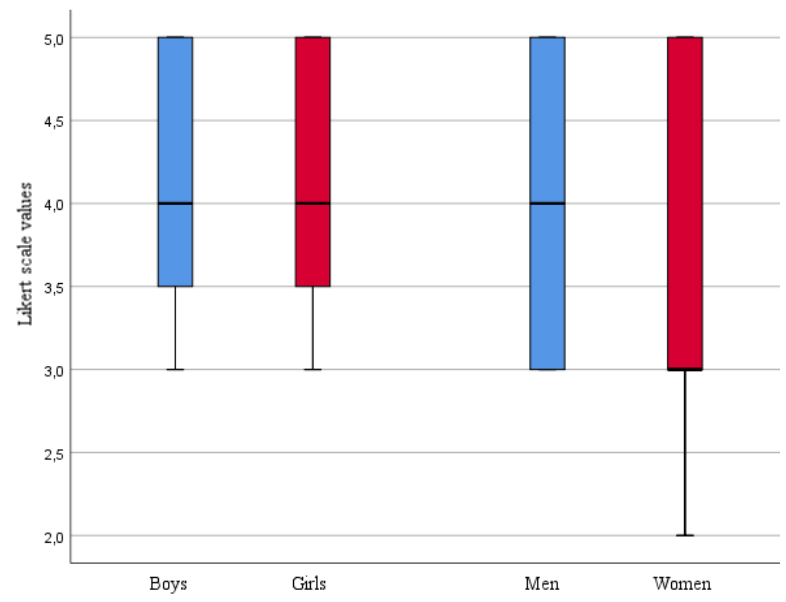

Figure 1. Perceived skills to use ICT.

\subsection{Social media, web services, and needs}

Moving on to the applied social media, other web services and the asylum seekers needs. In general, the (social) media services are employed to a big extent.

Some restrictions were mentioned by the participants. As some services are inhibited or not as widely used in their home country, they did not adapt them. For example, "some services are restricted by the government in Iran, therefore new ones need to be developed," as one man (IP4) expresses.

Another man (IP23) discloses: "In Turkey, live streaming is not allowed, therefore I do not use it" and "we are not allowed to use Wikipedia in Turkey," "in Turkey, the younger generation does not use Facebook, only 'older people' are using it. It is different to Germany, here, you need to use Facebook when you are young." One boy (IP27) proclaims "my parents have restricted the functions on my smartphone. I am not able to use social media or to download apps from the Google Play Store. And even for YouTube, I am only allowed to use YouTube Kids.”

Children and adolescents are using (social) media to find information and knowledge and to learn German. "I am even able to translate everything via Apps and to learn German via YouTube,” one girl (IP28) tells us. It is also used as a tool for homework. "For my homework, I always use YouTube and Google," "I use YouTube to learn about school topics and for my homework," disclose a girl and a boy (IP33 and IP37 respectively). As for the adults, "information about jobs is most important," proclaims one woman (IP24). Another woman states "when there was war in my country I used Twitter to get information about the city I lived in” (IP3).

Others are actively trying to avoid some form of knowledge. One woman explains (IP24): “I don’t want 
Table 3. Gender-dependent differences of motivations to use web services; Male N=28, Female $\mathrm{N}=\mathbf{1 7}$.

\begin{tabular}{l|c|c|c|c|c|c|c|c}
\hline \multicolumn{1}{|c|}{ Web Service } & \multicolumn{2}{|c|}{ Information } & \multicolumn{2}{c|}{ Entertainment } & \multicolumn{2}{c|}{ Social Interaction } & \multicolumn{2}{c}{ Self-Presentation } \\
\cline { 2 - 8 } & $\begin{array}{c}\text { Male } \\
\mathrm{N}=27\end{array}$ & $\begin{array}{c}\text { Female } \\
\mathrm{N}=17\end{array}$ & $\begin{array}{c}\text { Male } \\
\mathrm{N}=28\end{array}$ & $\begin{array}{c}\text { Female } \\
\mathrm{N}=17\end{array}$ & $\begin{array}{c}\text { Male } \\
\mathrm{N}=27\end{array}$ & $\begin{array}{c}\text { Female } \\
\mathrm{N}=15\end{array}$ & $\begin{array}{c}\text { Male } \\
\mathrm{N}=17\end{array}$ & $\begin{array}{c}\text { Female } \\
\mathrm{N}=15\end{array}$ \\
\hline WhatsApp & $77.8 \%$ & $88.2 \%$ & $39.3 \%$ & $64.7 \%$ & $88.9 \%$ & $88.9 \%$ & $58.8 \%$ & $60.0 \%$ \\
\hline YouTube & $88.9 \%$ & $70.6 \%$ & $89.3 \%$ & $88.2 \%$ & 0 & 0 & $5.9 \%$ & 0 \\
\hline Facebook & $63.0 \%$ & $58.8 \%$ & $42.9 \%$ & $41.2 \%$ & $37.0 \%$ & $50 \%$ & $70.6 \%$ & $40.0 \%$ \\
\hline Instagram & $48.1 \%$ & $35.3 \%$ & $42.9 \%$ & $23.5 \%$ & $22.2 \%$ & $11.1 \%$ & $47.1 \%$ & $26.7 \%$ \\
\hline Twitter & $25.9 \%$ & $5.9 \%$ & $3.6 \%$ & 0 & 0 & $5.6 \%$ & 0 & 0 \\
\hline Reddit & 0 & 0 & $3.6 \%$ & 0 & 0 & 0 & 0 & 0 \\
\hline Live Stream. & $3.7 \%$ & 0 & $7.1 \%$ & 0 & $3.7 \%$ & 0 & 0 & 0 \\
\hline 9 Gag & NA & NA & 0 & $5.9 \%$ & NA & NA & NA & NA \\
\hline TikTok & NA & NA & $25.0 \%$ & $29.4 \%$ & $7.4 \%$ & $5.6 \%$ & $29.4 \%$ & $26.7 \%$ \\
\hline Snapchat & NA & NA & 0 & $17.6 \%$ & $7.4 \%$ & $16.7 \%$ & $11.8 \%$ & $20.0 \%$ \\
\hline Apps & NA & NA & $75.0 \%$ & $41.2 \%$ & NA & NA & NA & NA \\
\hline Search Engine & $100 \%$ & $88.2 \%$ & NA & NA & NA & NA & NA & NA \\
\hline Website news & $29.6 \%$ & $29.4 \%$ & NA & NA & NA & NA & NA & NA \\
\hline Wikipedia & $37.0 \%$ & $17.6 \%$ & NA & NA & NA & NA & NA & NA \\
\hline
\end{tabular}

to read, see, or hear about news from my home country-it hurts me," and "my home country is destroyed, so I am not looking for information and news about it," states one man (IP9). To observe the information critically is important: "For a good understanding about the news you always have to consider various news portals-Russian, USAmerican, and different European ones-because politics are opinion-forming,” as one man (IP20) states. Another man (IP13) explains: "There are a lot of fake news on Facebook, you have to be careful about what you believe." Even social media traditionally used for social interaction is utilized to gather information: "I have many WhatsApp groups to stay up-to-date and to get information," reports one man (IP23). Other channels like YouTube are employed as well: "I'm using YouTube for everything, there is a lot of information on YouTube," and "YouTube is better than everything else, there are all information you will need," as two men (IP4 and IP7 respectively) explain.

Children like to use (social) media to entertain themselves; especially TikTok was mentioned in this context: "Making videos on TikTok is a lot of fun, but I do not show myself in the videos I make, they are always about other things," tells one boy (IP40). Another boy confirms (IP45): "Of course I use TikTok to make videos, but not about myself, I prefer to create them about other things." When it comes to adults and entertainment, one man states (IP25) "there is no time for entertainment." A sentiment shared by other asylum seekers, as was outlined before.

Social media plays an important role for social interaction and staying in contact with family and friends from Germany as well as their home country. "With my friends and family I can share all my experiences via WhatsApp, I can send them pictures of my whole day," proclaims one girl (IP33).
One boy tells us (IP40) "my grandmother lives in Syria; we are writing and talking via Facebook.” For some adults, this is the only priority when it comes to social media: "I deleted all my social media accounts except WhatsApp to stay in contact with my family and friends," as one woman (IP24) emphasizes. One man (IP1) says "sometimes we are talking with video calls or audio calls via WhatsApp." For others, social media lost its appeal: "I used to interact on a lot of different social networking services, but since I am in Germany, I do not,” explains one man (IP20).

Concerning self-presentation, the children use it also as a medium to interact with other people. A boy (IP34) says "I upload pictures on Instagram and Facebook to show everybody what I am doing and to get in contact with new people." One girl states "I post things on Facebook and WhatsApp, it is fun and leads to conversations with others” (IP36). Another girl (IP42) also mentions "I make my own videos on TikTok where I am singing. It is a lot of fun and my friends like it." Regarding self-presentation and adults, a woman (IP15) expresses: "On WhatsApp, Facebook, and Instagram I upload pictures, so people who know me see all the news about my life and it is fun." "Posting things online and self-presentation is a lot of fun," confirms one man (IP21). Self-presentation is also a form of distributing good news. A father (IP25) told us "I share posts online to tell everyone that my family is fine and that we are all spending time together. It makes me happy.”

3.3.1. Gender-dependent differences. The applied social media and other web services in order to satisfy the different needs according to the Uses and Gratifications Theory can be observed in Table 3 for the gender-dependent differences. 
Table 4. Age-dependent differences of motivations to use web services; Young $\mathrm{N}=\mathbf{2 2}$, Adult $\mathrm{N}=\mathbf{2 4}$.

\begin{tabular}{l|c|c|c|c|c|c|c|c}
\hline \multirow{2}{*}{ Web Service } & \multicolumn{2}{|c|}{ Information } & \multicolumn{2}{c|}{ Entertainment } & \multicolumn{2}{c|}{ Social Interaction } & \multicolumn{2}{c}{ Self-Presentation } \\
\hline Woung & $\mathrm{N}=20$ & $\begin{array}{c}\text { Adult } \\
\mathrm{N}=24\end{array}$ & $\begin{array}{c}\text { Young } \\
\mathrm{N}=21\end{array}$ & $\begin{array}{c}\text { Adult } \\
\mathrm{N}=24\end{array}$ & $\begin{array}{c}\text { Young } \\
\mathrm{N}=19\end{array}$ & $\begin{array}{c}\text { Adult } \\
\mathrm{N}=24\end{array}$ & $\begin{array}{c}\text { Young } \\
\mathrm{N}=13\end{array}$ & $\begin{array}{c}\text { Adult } \\
\mathrm{N}=19\end{array}$ \\
\hline YouTtubp & $80.0 \%$ & $83.3 \%$ & $33.3 \%$ & $62.5 \%$ & $75.0 \%$ & $100 \%$ & $53.8 \%$ & $63.2 \%$ \\
\hline Facebook & $75.0 \%$ & $87.5 \%$ & $90.5 \%$ & $87.5 \%$ & 0 & 0 & $7.7 \%$ & 0 \\
\hline Instagram & $40.0 \%$ & $69.2 \%$ & $14.3 \%$ & $66.7 \%$ & $15.0 \%$ & $62.5 \%$ & $23.1 \%$ & $78.9 \%$ \\
\hline Twitter & $35.0 \%$ & $50.0 \%$ & $38.1 \%$ & $33.3 \%$ & $5.0 \%$ & $25.0 \%$ & $38.5 \%$ & $36.8 \%$ \\
\hline Reddit & $10.0 \%$ & $25.0 \%$ & 0 & $4.2 \%$ & 0 & $4.2 \%$ & 0 & 0 \\
\hline Live Stream. & $5.0 \%$ & 0 & 0 & $4.2 \%$ & 0 & 0 & 0 & 0 \\
\hline 9Gag & NA & NA & $9.5 \%$ & 0 & 0 & $4.2 \%$ & 0 & 0 \\
\hline TikTok & NA & NA & $42.9 \%$ & $12.5 \%$ & $5.0 \%$ & $8.3 \%$ & $46.2 \%$ & $15.8 \%$ \\
\hline Snapchat & NA & NA & $9.5 \%$ & $4.2 \%$ & $10.0 \%$ & $8.3 \%$ & $30.8 \%$ & $5.3 \%$ \\
\hline Apps & NA & NA & $90.5 \%$ & $37.5 \%$ & NA & NA & NA & NA \\
\hline Search Engine & $95.0 \%$ & $95.8 \%$ & NA & NA & NA & NA & NA & NA \\
\hline Website news & $5.0 \%$ & $50.0 \%$ & NA & NA & NA & NA & NA & NA \\
\hline Wikipedia & $25.0 \%$ & $33.3 \%$ & NA & NA & NA & NA & NA & NA \\
\hline Netflix & NA & NA & $33.3 \%$ & $20.8 \%$ & NA & NA & NA & NA \\
\hline
\end{tabular}

Regarding the need for information, all female and almost all male interviewees are in need of them (96.4\%). Overall, search engines (m 100\%, f 88.2\%), YouTube (m 88.9\%, f 70.6\%), as well as WhatsApp (m $77.8 \%$, f $88.2 \%$ ) are used the most often to get information.

The male participants use Facebook (63.0\%), Instagram (48.1\%), Twitter (25.9\%), and live streaming services (3.7\%) more than the female ones.

All participants like to use some kind of (social) media to entertain themselves. YouTube is the most applied social media service by both groups (m 89.3\%, f $88.2 \%)$. For female participants, they like to use WhatsApp (64.7\%) and Snapchat (17.6\%) and therefore interaction with others as a form of entertainment much more than male users (WhatsApp $39.3 \%$, Snapchat $0 \%$ ). For the male participants, they are the only ones that use Twitter (3.6\%), Reddit (3.6\%), and Live Streaming (7.1\%) for entertainment purposes. They also use Apps as, for instance, games (75.0\%) much more than female participants (41.2\%).

Social interaction is sought by all female participants and almost all male participants (96.4\%). WhatsApp is used the most often by both genders (m 88.9\%, f 88.9\%). Female participants are more inclined to use Facebook (50.0\%), Twitter (5.6\%), and Snapchat $(16.7 \%)$ for social interaction in contrast to the male participants (Facebook 37.0\%, Twitter 0\%, Snapchat $7.4 \%$ ). The male participants use Instagram (22.2\%) and Live Streaming (3.7\%) more than the female interviewees.

If the self-presentation aspect is concerned, more female $(88.2 \%)$ than male participants $(60.7 \%)$ are interested in it. Most of the male participants like to use Facebook (70.6\%) and WhatsApp (58.8\%) to present themselves.
Female participants prefer WhatsApp (60.0\%) overall. More male participants apply Instagram (47.1\%) and YouTube (5.9\%) than the female interviewees (Instagram 26.7\%, YouTube 0\%) for self-presentation.

3.3.2. Age-dependent differences. Differences for the applied social media and web services to satisfy the four needs suggested by the U\&GT can be identified for the two age groups (Table 4).

All of the older users $(100 \%)$ and almost all younger users (95.2\%) search for information on the internet. Most of the interviewees like to use search engines to find information (children 95.0\%, adults $95.8 \%)$. Significantly more adults $(50.0 \%)$ visit news websites to gather information than the younger ones $(5.0 \%)$. When looking at social media, the older participants also employ YouTube (87.5\%), Instagram (50.0\%), and Twitter (25.0\%) more, especially Facebook (69.2\%). Live streaming is only used by the young participants (5.0\%).

If the motivational factor entertainment is concerned, all participants want to satisfy this need by using social media or web services. YouTube is the preferred medium for both groups overall (young 90.5\%, adults 87.5\%), but also gaming Apps for the youngest users $(90.5 \%)$ with a significant difference. WhatsApp (62.5\%), Twitter (4.2\%), and Reddit (4.2\%) are more used by adults, as the younger ones do not use Twitter or Reddit at all. Live Streaming is only applied by the younger users (9.5\%), and especially TikTok $(42.8 \%)$ is favored by the younger participants.

Social interaction is sought by all adults and almost all children and adolescents (90.5\%) on social media. The most applied service is WhatsApp for both groups (young $75.0 \%$, adults $100 \%$ ), but is preferred by adults. Adults also use live streaming services (4.2\%), TikTok 
(8.3\%), Twitter (4.2\%), Instagram (25.0\%), and especially Facebook (62.5\%) more often to interact with others.

To present oneself is important for $61.9 \%$ of the children or adolescents and to $79.2 \%$ of the adults. Here, Facebook is used the most often by adults (78.9\%); however, WhatsApp (53.8\%) is applied more often by the younger participants. The latter also like to use Snapchat (30.8\%) and TikTok (46.2\%) for this matter.

\section{Discussion and limitations}

The results of this study offer insight into the ageand gender-dependent differences of asylum seekers' ICT and online media usage (RQ1), their perceived skills to use ICT (RQ2), and their motives to apply (social) media (RQ3) after their arrival in Germany. For this purpose, semi-structured interviews and a survey were conducted. 45 participants from the Middle East were interviewed. Most of the participants use a smartphone, the internet, and the TV. For nearly all children the smartphone replaces many other ICTs, they are watching movies on it like they normally did on television, they even look up information and can do all the things on their smartphone instead of using a notebook or computer. Some younger children got restrictions from their parents and are not even allowed to own a smartphone. When it comes to the perceived ability to interact with ICT, children in general had higher confidence than adults.

Adults, men and women alike, often mentioned that they do not have free time, in contrast to back in their home country, to use their smartphones or (social) media anymore, since they are busy learning German, searching for a job, and caring for their childrenwhich has priority for them. The results showed that all adults do utilize (social) media in their free time for entertainment, social interaction, and to find information, but not to which extend. But it is safe to assume from the interviews that they do not use it for many hours a day. This is in stark contrast to a study conducted with asylum seekers in the Netherlands. They mentioned that "the average amount of time spent on social media was seven hours per day. [...] Prior to their arrival in the Netherlands, participants from Syria reported using less social media due to their busy working schedules in their homeland" [3:1595f.]. This should be investigated further. Why does the application of social media differ this much for asylum seekers in two neighboring countries (Germany and the Netherlands)?

The governments of a few asylum seekers' home countries prohibit the usage of social media services and restrict the information on news portals and online information systems, therefore these services were also not adapted since arriving in Germany.

Although many of the adult asylum seekers are interested in information about their home country, some reported about the bad conditions, that there is sometimes no chance to get in contact with relatives and acquaintances, and that they do not want to get information or news about it. A few of the interviewed adult participants had a critical point of view about online information in general and about knowledge from social media systems, which is a sentiment shared by other asylum seekers [3]. Nonetheless, information is often sought after with the use of search engines, WhatsApp, and YouTube. This can be explained as "information" also includes details about the wellbeing of relatives, information from other asylum seekers about jobs, integration and so on, which can be satisfied with messaging services. For adults, this also includes Facebook and news websites. The interviewed children often mentioned the usage of web-based systems, the search engine Google, the video-sharing platform YouTube or WhatsApp groups for doing their homework and finding information for it. When it comes to entertainment, YouTube is a central system, for consuming music and movies, for all age groups and genders. TikTok was highly favored among the boys and girls, as well as different gaming apps, but more by the male participants. Surprisingly, selfpresentation e.g. posting pictures or short videos of oneself, for example on Instagram or especially TikTok, is a form of social interaction for a few boys and girls. The older interviewees share pictures to show their family members in their home country how they experience their new life in Germany. The importance of smartphones and social media to stay in contact with family was emphasized in other studies as well [3,29].

Overall, Facebook and Twitter do not have a significant status for children and adolescents. This can be attributed to a general trend in social media usage, as younger users are adapting to new services and abandon the traditional ones [20].

Some limitations of this study should be discussed. First, the interview citations do not reflect the opinion of all asylum seekers, even of all interview participants, of course, but sometimes, a few trends or the general mood could be detected. For a statistical analysis, the number of participants is rather small, but helped us to gain first insights into the (social) media and ICT usage.

For future research, it will be interesting to see if the social media usage of asylum seekers changes or adapts to the behavior of German residents, or if there are any differences even. In contrast to Germany, countries' immigration offices use social media in 
order to help the asylum seekers to integrate into society [3]. Furthermore, research should determine what kind of information asylum seekers need and are searching for on (social) media. Some participants also stated that they do have difficulties integrating into the German society since it is not easy to establish contact with Germans, due to language barriers, time constraints, but also, to the German nature and attitude. This sentiment was shared by asylum seekers even in the Netherlands: "For me... what I notice is that Dutch people like refugees. There is no racism in the Netherlands. In Germany and Sweden, the case is different, refugees are suffering there" [3:1597]. Surely, Germany offers many different initiatives for asylum seekers to integrate into society and establish contact with German people, but still, this point of view tells an aspect of a different story. The smartphone plays an essential part in immigration and integration, as the asylum applicants can translate, search for information and stay in contact with relatives through the medium. Hopefully, this research is a first step into the direction to help asylum seekers and their integration into a new life.

Acknowledgements. We want to thank Mohamed Abdillah for his translations before and during the interviews. Special thanks to Rasia Haji and her help in getting into contact with the AWO, and thanks to the AWO in Wesel and Moers for letting us interview the refugee children.

\section{References}

[1] K. Aal, A. Weibert, R. Talhouk, V. Vlachokyriakos, K. Fisher, and V. Wulf, "Refugees \& technology: Determining the role of HCI research", in Proceedings of GROUP' 18, ACM, NY, 2018, pp. 362-364.

[2] K. Aal, G. Yerousis, K. Schubert, D. Hornung, O. Stickel, and V. Wulf, “Come_in@palestine: Adapting a German computer club concept to a Palestinian refugee camp” in Proceedings of the 5th ACM international conference on Collaboration across boundaries: culture, distance \& technology, ACM, NY, 2014, pp. 111-120.

[3] A. Alencar, "Refugee integration and social media: a local and experiential perspective”, Information, Communication \& Society, 21(11) 2017, pp. 1588-1603.

[4] Amnesty International, What's the difference between a refugee and an asylum seeker? Amnesty.org. https://www.amnesty.org.au/refugee-and-an-asylum-seekerdifference/

[5] R. Aylett, M. Kriegel, M.Y. Lim, J. Dias, K. Leichtenstern, W.C. Ho, and P. Rizzo, "ORIENT: Interactive agents for stage-based role-play”, in Proceedings of The 8th International Conference on Autonomous Agents and Multiagent Systems - Volume 2, IFAAMAS, Richland, 2009, pp. 1371-1372
[6] K. Bansak, J. Hainmueller, and D. Hangartner, "How economic, humanitarian, and religious concerns shape European attitudes toward asylum seekers”, Science, 54(6309), AAAS, Washington, D.C., 2016, pp. 217-222.

[7] J. Baranoff, R. Israel Gonzales, J. Liu, Yang, and J. Zheng, "Lantern: Empowering refugees through communitygenerated guidance using near field communication" in Proceedings of the 33 Annual ACM CHI'15, ACM, NY, 2015, pp. 7-12.

[8] V. Barker, “Older adolescents' motivations for social network site use: The influence of gender, group identity, and collective self-esteem”, CyberPsychology \& Behavior, Mary Ann Liebert, Inc., New York, 12(2), 2009, pp. 209-213.

[9] K. Bisimwa, I. Brown, and K. Johnston, "Mobile phone use by urban refugees in South Africa: Opportunities and challenges", in Proceedings of HICSS 2018, IEEE Society, Washington, D.C., 2018, pp. 2161-2170.

[10] Blumler, J.G., and E. Katz, The uses of mass communications: Current perspectives on gratifications research, Sage, Newbury Park, 1974.

[11] Bourgeais, V., and Juchno, P., "Asylum in the EU member states”, Eurostat Newsrelease, 44, 2017, 6 pp.

[12] Case, D.O., and L.M. Given, Looking for information. A survey of research on information seeking, needs, and behavior, 4th ed., Emerald, Bingley, 2018.

[13] Cole, C., Information need. A theory connecting information search to knowledge formation, Information Today, Medford, 2012.

[14] J.W. Cressweel, V.L. Plano Clark, M.L. Gutmann, and W.E. Hanson, "Advanced mixed methods research design", in Handbook of mixed methods in social \& behavioral research, Sage, Thousand Oaks, CA, 2003, pp. 209-240.

[15] R. Dekker, G. Engbersen, J. Klaver, and H. Vonk, "Smart refugees: How Syrian asylum migrants use Social Media information in migration decision making", Social Media+Society, 4(1), Sage, Thousand Oaks, 2018, pp. 1-11.

[16] Eurostat, Asylum statistics. https://ec.europa.eu/eurostat/statistics-

explained/index.php/Asylum_statistics\#First-

time_applicants:_581_thousand_in_2018

[17] Federal Office for Migration and Refugees, Aktuelle Zahlen zu Asyl, Ausgabe: Dezember 2018 [Current data on asylum, edition: December 2018].

[18] Federal Office for Migration and Refugees, The stages of the German asylum procedure, BAMF, Nuremberg, 2019.

[19] K.J. Fietkiewicz, E. Lins, K.S. Baran, and W.G. Stock, "Inter-generational comparison of social media use: Investigating the online behavior of different generational cohorts", in Proceedings of HICSS 2016, IEEE, Washington, DC, 2016, pp. 3829-3838.

[20] K.J. Fietkiewicz, E. Lins, and A. Budree, "Investigating the generation- and gender-dependent differences in social media use: A cross-cultural study in Germany, Poland and South Africa”, in: Meiselwitz G. (ed.) SCSM 2018, Springer, Cham, 2018, pp. 183-200.

[21] K.E. Fisher, and H. Julien, "Information behavior", Annual Review of Information Science and Technology, 43, 2009, pp 317-358.

[22] R. Joiner, J. Gavin, J. Duffield, M. Brosnan, C. Crook, A. Durndell, P. Maras, J. Miller, A.J. Scott, P. Lovatt.: 
Gender, internet identification, and internet anxiety: Correlates of internet use. CyberPsychology \& Behavior, 8(4), Mary Ann Liebert, Inc., New York, 2005, pp. 371-378.

[23] A. Lenhart, K. Purcell, A. Smith, and K. Zickuhr, Social media \& mobile internet use among teens and young adults, Pew, Washington, DC, 2010.

[24] McQuail, D., Mass communication theory, Sage, London, 1983.

[25] Melnyk, A., "Information practices of the refugees and communication strategies in the integration system: The case of Afghans in Kronoberg County, Sweden”, Master's Thesis, Linneaus University, 2017.

[26] Ocepek, M.G., "Bringing out the everyday in everyday information behavior”, Journal of Documentation, 74(2), Emerald Group Publishing, Bingley, 2018, pp. 398-411.

[27] Park, J., Europe's migration crisis. cfr.org. https://www.cfr.org/backgrounder/europes-migration-crisis

[28] K. Pettigrew, R. Fidel, and H. Bruce, "Conceptual frameworks in information behavior", Annual Review of Information Science and Technology, 35, 2001, pp. 43-78.

[29] K.M. Perez, and M.M. Salgado, "Mobility and the mobile: A study of adolescent migrants and their use of the mobile phone”, Mobile \& Media Communication, 2019.

[30] Scarpetta, S., Skills for a digital world. OECD, 2016.

[31] K. Scheibe, F. Zimmer, and W.G. Stock, "Social media usage of asylum seekers in Germany”, in Proceedings of the $6^{\text {th }}$ European Conference on Social Media, Emerald Insight, Bingley, 2019, pp. 263-272.

[32] G. Shao, "Understanding the appeal of user-generated media: A uses and gratification perspective", Internet Research, 19(1), Emerald Publishing Limited, Bingley, 2009, pp. 7-25.
[33] D.H. Sonnenwald, "Information Horizons", in K.E. Fisher, S. Erdelez and L.(E.F.) McKechnie (Eds.), Theories of Information Behavior, Information Today, Medford, 2005, pp. 191-197.

[34] J. Stiller, and V. Trkulja, “Assessing Digital Skills of Refugee Migrants During Job Orientation in Germany”, in iConference 2018, LNCS 10766, Springer, Cham, 2018, pp. 527-536.

[35] United Nations High Commissioner for Refugees (UNHCR). Connecting refugees: How Internet and mobile connectivity can improve refugee well-being and transform humanitarian action. Retrieved from http://www.unhcr.org/5770d43c4 (2016).

[36] Wang, Y.-C., Burke, M., Kraut, R.: Gender, topic, and audience response: An analysis of user-generated content on Facebook. In: Proceedings of the SIGCHI Conference on Human Factors in Computing Systems, pp. 31-34. ACM, New York (2013).

[37] A.M. Williams, and V. Baláž, "Migration, risk, and uncertainty: Theoretical perspectives”, Population, Space and Place, 18, Wiley, New Jersey, 2012 pp. 167-180.

[38] T.D. Wilson, "Human information behavior”, Informing Science: The International Journal of Emerging Transdiscipline, 3(2), 2000, pp. 49-55.

[39] Y. Xu, C. Maitland, and B. Tomaszewski, "Promoting participatory community building in refugee camps with mapping technology" in Proceedings of the Seventh International Conference on Information and Communication Technologies and Development, ACM, NY, 2015, pp. 1-4. 